\title{
Uranium Ore Dust
}

National Cancer Institute

\section{Source}

National Cancer Institute. Uranium Ore Dust. NCI Thesaurus. Code C29777.

Resulting from mining of radioactive heavy metal uranium, Uranium Ore Dust presents chemical and radiological hazards linked to inducing cancer. The major uranium isotope, U-238 has a long half-life while U-235 with shorter half-life emits gamma rays and alpha particles. Ore dust emits primarily alpha radioactivity; gamma radiation comes from associated radium and bismuth elements that result from radioactive uranium decay. During mining, toxic radon gas can also escape into the air and seep into surface water and groundwater. ( $\mathrm{NCl} 04)$ 